\title{
Eddy covariance measurements of sea spray particles over the Atlantic Ocean
}

\author{
S. J. Norris ${ }^{1}$, I. M. Brooks ${ }^{1}$, G. de Leeuw ${ }^{1,2}$, M. H. Smith ${ }^{1}$, M. Moerman ${ }^{3}$, and J. J. N. Lingard ${ }^{1}$ \\ ${ }^{1}$ School of Earth and Environment, University of Leeds, Leeds, LS2 9JT, UK \\ ${ }^{2}$ University of Helsinki, Dept. of Physical Sciences, Helsinki, Finland \& Finnish Meteorological Institute, Climate and Global \\ Change Unit, Helsinki, Finland \\ ${ }^{3}$ TNO, Defence and Security, The Hague, The Netherlands
}

Received: 17 August 2007 - Published in Atmos. Chem. Phys. Discuss.: 11 September 2007

Revised: 13 November 2007 - Accepted: 8 January 2008 - Published: 7 February 2008

\begin{abstract}
Most estimates of sea spray aerosol source functions have used indirect means to infer the rate of production as a function of wind speed. Only recently has the technology become available to make high frequency measurements of aerosol spectra suitable for direct eddy correlation determination of the sea spray particle flux. This was accomplished in this study by combining a newly developed fast aerosol particle counter with an ultrasonic anemometer which allowed for eddy covariance measurements of sizesegregated particle fluxes. The aerosol instrument is the Compact Lightweight Aerosol Spectrometer Probe (CLASP) - capable of measuring 8-channel size spectra for mean radii between 0.15 and $3.5 \mu \mathrm{m}$ at $10 \mathrm{~Hz}$. The first successful measurements were made during the Waves, Air Sea Fluxes, Aerosol and Bubbles (WASFAB) field campaign in October 2005 in Duck (NC, USA). The method and initial results are presented and comparisons are made with recent sea spray source functions from the literature.
\end{abstract}

\section{Introduction}

Sea spray particles are salt water droplets ejected from the ocean. The aerosols formed from sea spray particles are important because they have a significant impact on climate processes, both directly via the scattering of solar radiation, and indirectly via their influence on cloud microphysical properties. Sea salt particles are the single most important factor controlling the scattering of solar radiation and, hence, the radiation budget near the surface under cloud free conditions over the open oceans (Haywood et al., 1999). They dominate the particulate mass concentration in unpolluted marine air and contribute approximately $44 \%$ to the global

Correspondence to: S. J. Norris

(s.norris@see.leeds.ac.uk) aerosol mass flux into the atmosphere (Seinfeld and Pandis, 1998). They act as cloud condensation nuclei and have a large influence on both the microphysics and chemistry of marine stratocumulus clouds (O'Dowd et al., 1999), which are one of the largest sources of uncertainty in climate predictions. They have a large range of sizes, with dry radii from $0.01 \mu \mathrm{m}$ up to $100 \mu \mathrm{m}$ (Mårtensson et al., 2003; Clarke et al., 2006).

Sea spray aerosol droplets are produced by several different mechanisms. Jet and film droplets are produced from bursting bubbles. Bubbles form predominantly from breaking waves, but there are many other possible production mechanisms: biological processes, de-gassing of air-rich surface layers as water is warmed, volcanic release of gases, and rain impacting on the ocean surface. For $10-\mathrm{m}$ wind speeds above about $5 \mathrm{~m} \mathrm{~s}^{-1}$ the wind stress at the ocean surface is sufficient to cause breaking waves (Lewis and Schwartz, 2004). As they break, the waves entrain air into the water producing a plume of bubbles (Blanchard and Woodcock, 1980). As the bubbles reach the ocean surface, patches of white foam form - whitecaps. As a bubble protrudes above the ocean surface some of the liquid film surrounding the bubble drains off, thinning and weakening the film. The film ruptures and rolls back on itself before producing film droplets (Blanchard and Woodcock, 1980; Spiel, 1998). Jet droplets are produced when the pressure is released from inside the bubble as it collapses. A liquid jet shoots up from the base of the bubble cavity due to hydrostatic forces, quickly becomes unstable and breaks into a small number of jet droplets (Blanchard, 1983).

The sea spray source function (SSSF) describes the amount (number, volume, mass) of sea spray aerosol produced at the sea surface per unit time and area as a function of environmental conditions. SSSF's available in the literature vary by as much as 6 orders of magnitude (Andreas, 1998, 2002); however, results from recent work in the

Published by Copernicus Publications on behalf of the European Geosciences Union. 
sub-micron size-range converge to within about a factor of about 7 (Clarke et al., 2006). Most of the source functions are derived from indirect methods, relying either on an assumption of steady state in the atmosphere or the whitecap method. In the former the production flux is assumed equal to a known deposition flux (e.g., Andreas, 1992; Smith et al., 1993; Fairall et al., 1994; Smith and Harrison, 1998); in the latter a parameterization of the fractional whitecap cover, based on field observations, is combined with laboratory measurements of the sea spray aerosol production rate per unit area of whitecap (e.g. Monahan et al., 1986; Mårtensson et al., 2003). For recent formulations of the sea spray source function, see Schulz et al. (2004) and O'Dowd and de Leeuw (2007).

There are potential problems associated with the assumption of steady state leading to balance between production and removal of sea spray particles (e.g., Fairall et al., 1994; Smith et al., 1993; Smith and Harrison, 1998). A direct measurement of the aerosol flux would eliminate some, though not all, of these problems, and would be expected to result in a physically more robust source function. The ideal approach to turbulent flux measurement is eddy covariance. This method has been used to measure particle deposition to forests (Gallagher et al., 1997; Buzorius et al., 1998) and recently also to look at the production flux of sea salt particles (Nilsson et al., 2001; Geever et al., 2005). The eddy covariance method correlates turbulent fluctuations of the vertical wind component with those of particle concentration. The vertical wind speed is usually measured with an ultrasonic anemometer. The vertical turbulent flux is obtained from the equation for total vertical flux via Reynolds averaging (see Stull, 1988). Application of the EC method requires an instrument that can measure aerosol concentrations with a high temporal resolution - eddy correlation requires a minimum instrument response of $2-3 \mathrm{~Hz}$ - combined with a high sample volume in order to achieve robust statistics with low ambient particle concentrations. The measurements of sea spray fluxes that have been made to date have either not been size segregated or had a low temporal resolution. The number of measurements also remains sparse due to the bulky and expensive nature of most of the aerosol instrumentation, which makes it awkward to use close to the sea surface without either causing flow distortion or risking damage to the instrumentation in a hostile environment.

The eddy covariance method was first applied to the measurement of sea spray fluxes by Nilsson et al. (2001), who assembled a flux package consisting of a sonic anemometer and a Condensation Particle Counter (CPC). The CPC used had a temporal resolution of $3 \mathrm{~Hz}$ and measured the total particle concentration for radii larger than $10 \mathrm{~nm}$. Geever et al. (2005) used a flux package consisting of a sonic anemometer and two CPC's to determine fluxes in two very broad size ranges. de Leeuw et al. (2007) have recently made eddy covariance flux estimates in four coarse and overlapping size ranges using a Passive Cavity Aerosol Spectrome- ter Probe (PCASP). The PCASP time resolution is only $1 \mathrm{~Hz}$, however, so not all the turbulent fluctuations can be resolved.

The objective of this paper is to demonstrate the feasibility of making fully size-resolved sea spray flux measurements via eddy covariance using a novel aerosol instrument developed at the University of Leeds that couples a high sample volume to fast time response. The Compact Light-weight Aerosol Spectrometer Probe (CLASP) version used here can measure particles with ambient radii in the range $0.15 \mu \mathrm{m}$ to $3.5 \mu \mathrm{m}$. It has a flow rate of $50 \mathrm{ml} \mathrm{s}^{-1}$ and a sample rate of $10 \mathrm{~Hz}$. The main component of CLASP is a MetOne Optical Particle Counter (OPC) from Pacific Scientific Instruments. Particles in the MetOne sample volume scatter light from a laser (wavelength $780 \mathrm{~nm}$ ). The light scattered in the side lobes is detected by a photodiode; its intensity is a measure of the particle's size. In CLASP the MetOne OPC is connected to an 8 channel pulse height analyser to classify the peaks in output signal into 7 bins. See Hill et al. (2007) for more technical details of CLASP.

The CLASP instrument is especially suitable for insitu flux measurements in combination with an ultrasonic anemometer because of its small size (approximately $11 \times 15 \times 6 \mathrm{~cm})$ and light weight, which allows co-location with the sonic anemometer without causing significant flow distortion, and thus minimizing the length of inlet tube required (here approximately $0.5 \mathrm{~m}$ ) and hence particle losses. A high flow rate ensures that adequate statistics can be achieved to characterize spectra within a time period of approximately $10 \mathrm{~min}$, similar to the typical averaging time required for surface layer flux measurements.

\section{Field campaign}

The Waves, Air-Sea Fluxes, Aerosol and Bubbles (WASFAB) experiment (de Leeuw et al., 2007; Zappa et al., 2006) took place during October 2005 at the Army Corps of Engineers Field Research Facility (FRF) in Duck, North Carolina. The aim of the overall project was to obtain a large set of measurements to help constrain the sea spray source function. The location in North Carolina was selected because of the $560 \mathrm{~m}$ long pier and supporting oceanographic and meteorological observations available at the site. The measurement site was located at the end of the pier, well beyond the surf zone. Initial micrometeorological measurements made at the same location during the winter of 2005/2006 demonstrated that the local drag coefficient compared favourably with that obtained from the TOGA-COARE bulk flux parameterization (Zappa et al., 2006); we thus have confidence that the site is reasonably representative of the open ocean under onshore wind conditions (directions from $5^{\circ}$ to $120^{\circ}$ ).

The flux package used here (Fig. 1) consisted of a Gill R3A ultrasonic anemometer and CLASP, and was situated on a lattice tower at $16.5 \mathrm{~m}$ above the mean sea surface at the end of the pier. The measurements were supported by a second 


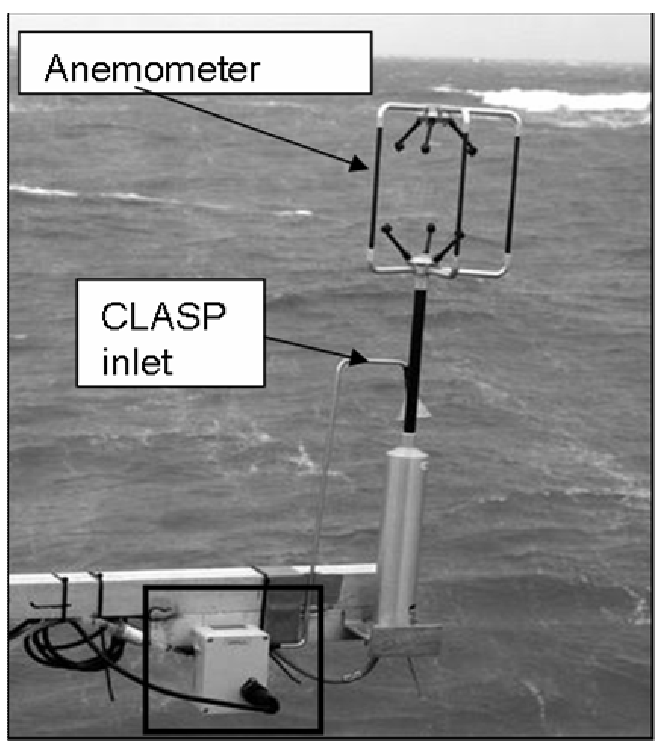

Fig. 1. Flux system consisting of the ultrasonic anemometer and the CLASP sensor (black cube) mounted at the end of a metal arm. The CLASP inlet tube can be kept short, roughly $0.5 \mathrm{~m}$, because the sensor of CLASP is very small and thus does not perturb the air flow to the ultrasonic anemometer.

aerosol flux package consisting of an ultrasonic anemometer, CPC and OPC with a heated inlet at $300^{\circ} \mathrm{C}$ and a Licor LI-7500 open path $\mathrm{H}_{2} \mathrm{O} / \mathrm{CO}_{2}$ gas analyzer. Supporting instruments included a sea spray package consisting of three Particle Metric Systems instruments: the Forward Scattering Spectrometer, the Optical Aerosol Probe, and a PCASP to provided background aerosol spectra. Information on the mass of carboniferous aerosol in the air sample was provided by a Magee Scientific Aethalometer. Meteorological stations provided information on the local temperature, humidity, wind speed and direction; offshore buoys provided wave measurements.

Flux losses due to displacement between the sonic anemometer and the CLASP inlet were calculated using the method described in Kristensen et al. (1997) to be $0.2 \%$. The time delay between a particle entering the CLASP inlet tube and entering the MetOne sample volume was calculated to be $0.2 \mathrm{~s}$; this is in good agreement with the 2-sample offset obtained by determining the time lag required to maximize the covariance between the turbulent vertical velocity and the CLASP concentrations. This offset was applied to the CLASP time series prior to calculating the turbulent fluxes.

\section{Data processing}

It is important to ensure that the averaging time for flux calculations is sufficient for all eddy scales contributing to the turbulent flux of particles to be sampled by the flux package, but not so long that non-turbulent mesoscale variability

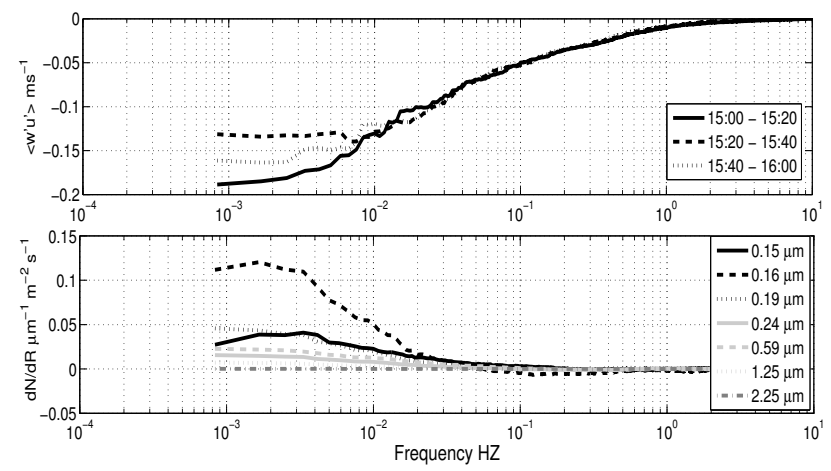

Fig. 2. Ogive curves for the momentum flux (top) and aerosol flux (bottom) for the sizes indicated in the legend. Each curve in the lower panel is the average of the three consecutive $20 \mathrm{~min}$ periods from 12 October shown in the upper panel.

is included. Very low frequency perturbations can be caused by non-stationarity of the local flow. Non-stationarity can occur during frontal passages, rapid boundary layer growth or decay, or other short-term boundary layer disturbances such as the passage of clouds. They can be identified as periods when the time series varies in a systematic, nonturbulent, way (Massman and Lee, 2002). An averaging time of about $30 \mathrm{~min}$ is generally considered a reasonable compromise (Massman and Lee, 2002). An appropriate averaging time for a given data set can be determined from the cumulative integral, from high frequency to low, of the cospectrum - the so-called Ogive function. Friehe et al. (1988) and Desjardins et al. (1989) used this method to find the minimum frequency contributed by turbulent eddies, and hence the minimum averaging time required to include all flux contributions. The frequency at which the slope of the Ogive curve levels off indicates the maximum scale of contributing eddies. Figure 2 shows example Ogive curves for the momentum and aerosol fluxes. The momentum flux is a good indicator of the scale of turbulent eddies; this levels off at around $0.003 \mathrm{~Hz}$ (approximately $5.5 \mathrm{~min}$ ). An averaging period of 20 min should thus encompass all contributing eddies, averaging several of the largest scale, and is used though-out this investigation. Some low-frequency variability remains visible in the ogives for aerosol flux. This is interpreted as being due to non-stationarity, or mesoscale variability, in the aerosol concentrations.

\subsection{Effects of aerosols other than sea spray}

In order to reliably estimate the flux of sea spray aerosol, it must be ascertained that the particles measured are indeed produced at the sea surface without significant contamination by non-sea spray particles. We thus require that the wind was onshore and the air mass sampled had resided over the ocean for between 3 and 4 days. During WASFAB, such conditions occurred only between 10 and 13 October 2005. Figure 3 


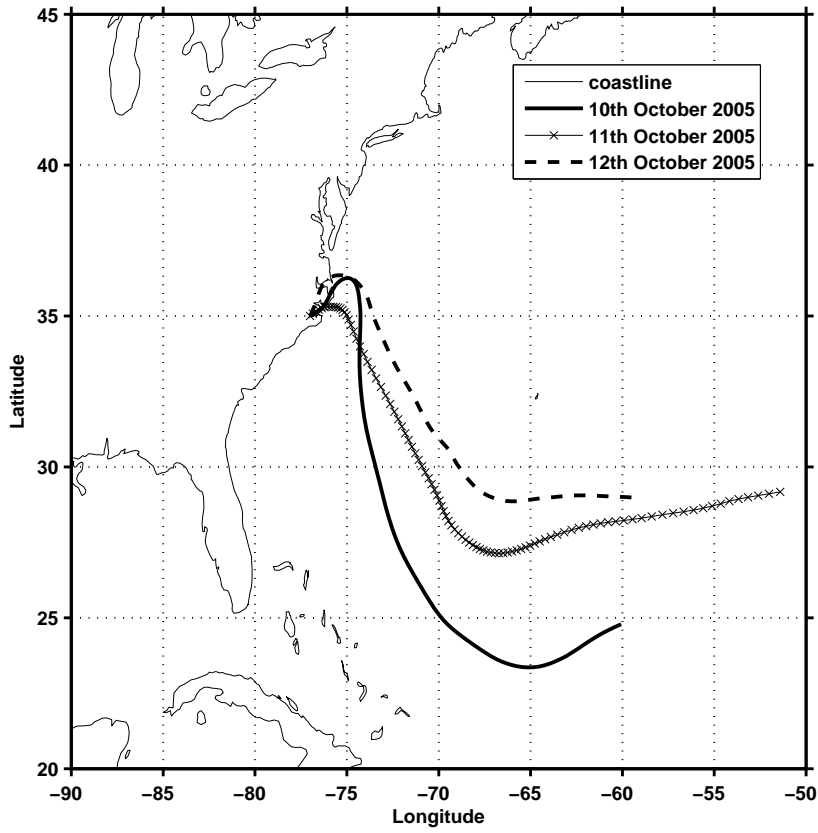

Fig. 3. Back trajectories from the NOAA Hysplit model for the 10 to 12 October 2005.

shows an example back trajectory from the NOAA Ready Hysplit model for 11 October.

Clean maritime air masses might still include non-sea-salt particles from di-methylsulphide (DMS) derived new particle formation or dust particles from the Saharan desert via long range transport. DMS-derived sulphate particle production is at its highest in the summer when stratification of the water column is greatest and the mixing depths are shallowest (Kiene, 1999), and occurs primarily over plankton blooms. DMS production can occur in October on the east US coast; however, there were no plankton blooms in the area during the field campaign and chlorophyll concentrations mapped by the NASA Terra satellite were below $1 \mathrm{mg} \mathrm{m}^{-3}$. Thus, we conclude there was limited biological activity to sustain local DMS production.

Any dust measured during this project would most likely originate in the Sahara and be transported into the atmosphere under high wind speed conditions. An examination of NASA Ozone Monitoring Instrument aerosol index images for the week preceding the October 11 indicates that there were no significant dust events in northern Africa. The aerosol index was consistently low for the northern part of Africa for the whole of September and October. Furthermore, air mass trajectories show that the air masses sampled had been over the ocean for at least 5 days and had turned back from the Northern American continent to a westerly course over the ocean before reaching the site in Duck. Hence it is very unlikely that dust would appear in these air masses in quantities significant enough to influence the measurements.

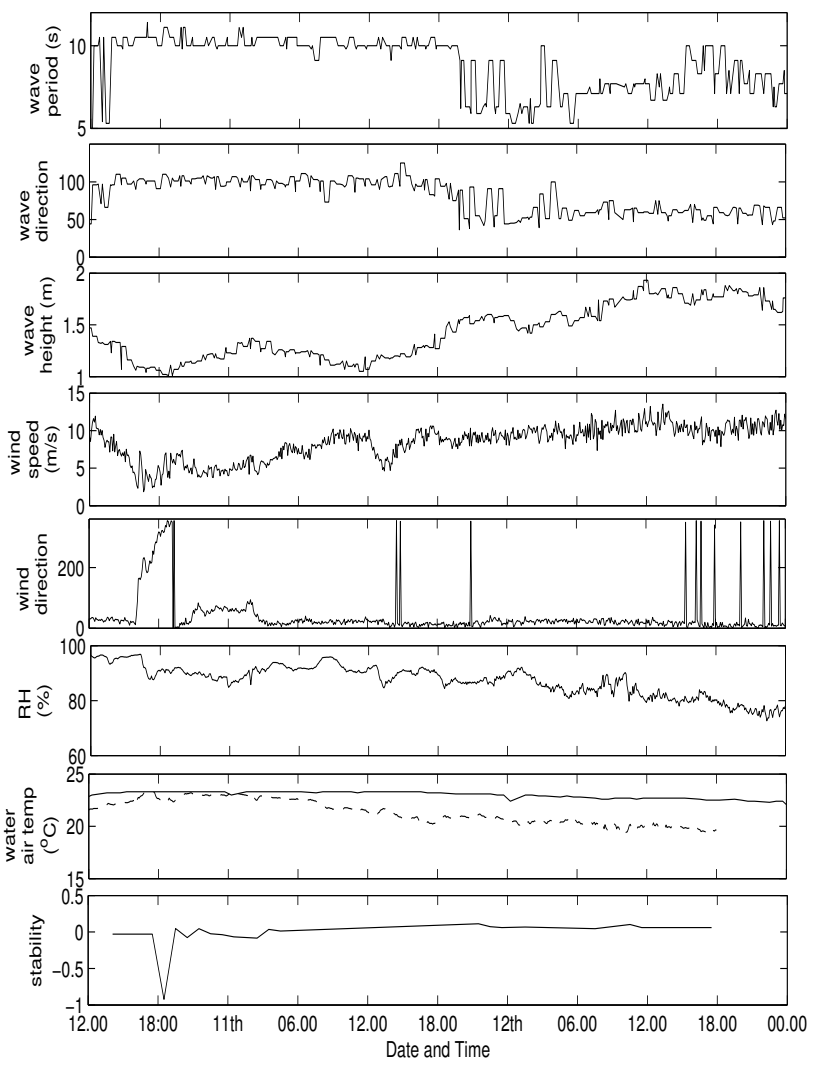

Fig. 4. Summary of the local meteorological and oceanic conditions over the onshore wind period between the 10 and the 12 October 2005 at the FRF pier in Duck, N.C. The dashed curve on the water and air temperature graph in the air temperature while the solid curve is the water temperature.

Any non-sea-salt aerosols originating elsewhere would only contribute to the deposition flux. The net flux measured with the eddy covariance method is the sum of the upward flux of particles locally produced at the sea surface and the downward flux of particles produced elsewhere and advected into the measurement region.

\section{Results}

4.1 Summary of local meteorological and oceanic conditions

Synoptic conditions between 10 and 12 October 2005 were dominated by a weak low pressure system that tracked just offshore of the east coast of the United States, moving from south to north. As it moved north the system deepened slightly and the wind speed increased from 3 to $12 \mathrm{~m} \mathrm{~s}^{-1}$ over the three days. Figure 4 shows a summary of the local meteorological and oceanic conditions during this time period. The wind direction remained consistently between $5^{\circ}$ and $120^{\circ}$, apart from a few short occasions, in particular during a short 

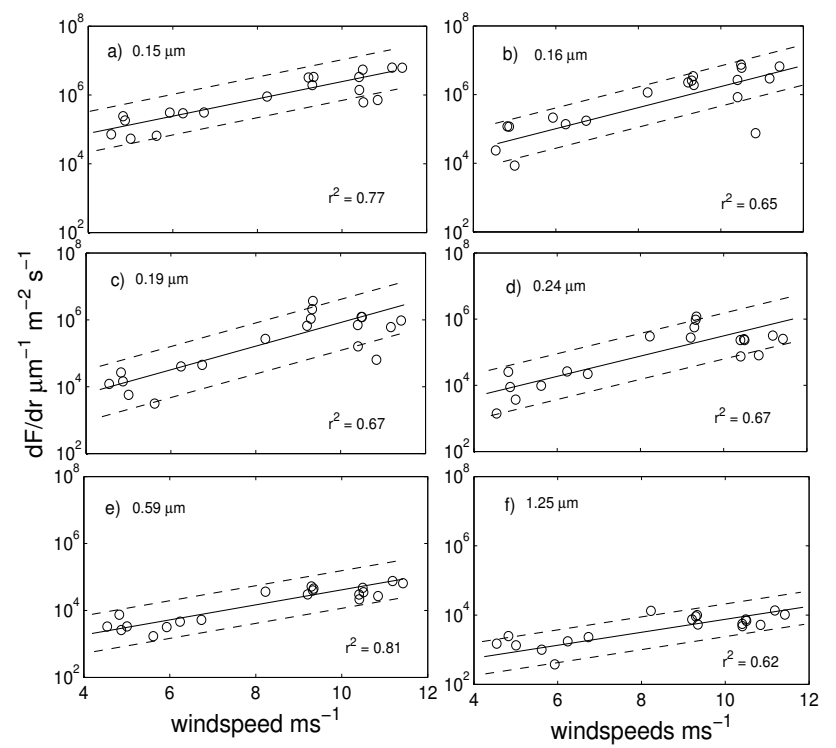

Fig. 5. Flux versus mean wind speed for mean particle radius (a) $0.15 \mu \mathrm{m}$, (b) $0.16 \mu \mathrm{m}$, (c) $0.19 \mu \mathrm{m}$, (d) $0.24 \mu \mathrm{m}$, (e) $0.5 \mu \mathrm{m}$, (f) $1.2 \mu \mathrm{m}$. Solid lines are log-linear fits to the data, dotted lines show the $95 \%$ confidence limits of the fit.

period from 15:00 till 19:00 UTC on the 10 October; data from these periods were excluded from the analysis. The mean half-hour averaged wave heights increased from approximately 1 to $2 \mathrm{~m}$ over the 3 days; the mean wave period remained almost constant at approximately $10 \mathrm{~s}$ up to 20:00 on 11 October, then decreased rapidly to approximately $5 \mathrm{~s}$ by 00:00 on 12 October; these changes, and an associated shift in the dominant wave direction were driven by the passage of the low pressure north offshore of the measurement site. Wave periods then increased slowly to $9 \mathrm{~s}$ by the end of 12 October, with a few short intervals of longer periods, corresponding with changes in wave direction. Both the air and water temperatures decreased over the measurement period; air temperature at a greater rate than the water temperature. The air-sea temperature difference is negative, providing a convective atmospheric surface layer, for all but one occasion over the period of 10 to 12 October. A positive air-sea temperature difference occurred at 01:00 on 11 October, and results from a drop in the water temperature which lasted for about $2 \mathrm{~h}$; this resulted in a short period of stable conditions in the atmospheric surface layer. For the majority of the measurement period the atmosphere was either unstable or near-neutral.

\subsection{Size segregated fluxes}

The data were first screened for wind sector. Only periods when the instruments were all working and the local wind direction was consistently between $5^{\circ}$ and $120^{\circ}$ were accepted, producing a total of 2020 -min averaged flux estimates, under a range of wind speeds from 4 to $12 \mathrm{~ms}^{-1}$.
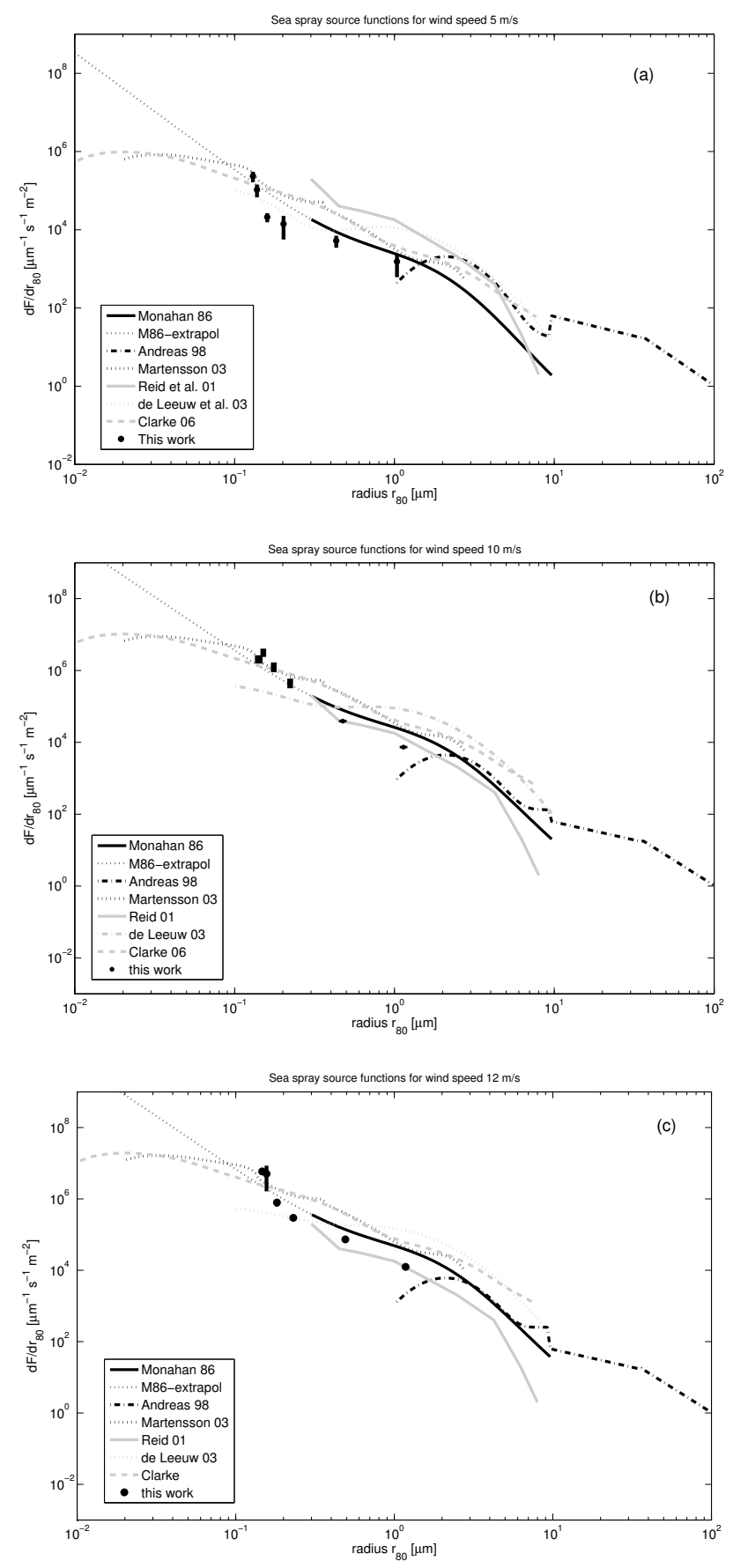

Fig. 6. Comparison of results from this work with a few sea spray source functions available in the literature for a number of different wind speeds (a) $5 \mathrm{~m}^{-1}$, (b) $10 \mathrm{~m} \mathrm{~s}^{-1}$, (c) $12 \mathrm{~m} \mathrm{~s}^{-1}$.

Figure 5 presents the particle fluxes as a function of the mean horizontal wind speed at the $10-\mathrm{m}$ level, for 6 of the 7 particle size bins. The 7th size bin is not shown because the Poisson statistics associated with low particle numbers at this largest size (aggravated by losses down the inlet tube) resulted in substantial signal noise. Log-linear fits to the data 
Table 1. Log-Linear fit parameters for each of the different particle sizes as functions of wind speed, $U_{10}$, and friction velocity, $u_{*}$.

\begin{tabular}{cccccccccc}
\hline CLASP channel & Mean size $(\mu \mathrm{m})$ & \multicolumn{3}{c}{ Bin size range $(\mu \mathrm{m})$} & \multicolumn{3}{c}{ Function of $U_{10}$} & \multicolumn{3}{c}{ Function of $u_{*}$} \\
\hline & & & $a$ & $b$ & $r^{2}$ & $a$ & $b$ & $r^{2}$ \\
\hline 1 & 0.15 & $0.145-0.155$ & 0.24 & 3.9 & 0.77 & 4.4 & 4.4 & 0.55 \\
2 & 0.16 & $0.155-0.165$ & 0.39 & 3.4 & 0.65 & 5.0 & 4.1 & 0.63 \\
3 & 0.19 & $0.165-0.21$ & 0.31 & 2.6 & 0.67 & 5.3 & 3.4 & 0.79 \\
4 & 0.24 & $0.21-0.27$ & 0.28 & 2.6 & 0.67 & 4.7 & 3.3 & 0.61 \\
5 & 0.59 & $0.27-0.9$ & 0.20 & 2.5 & 0.81 & 3.7 & 3.0 & 0.75 \\
6 & 1.25 & $0.9-1.6$ & 0.14 & 2.4 & 0.62 & 2.7 & 2.7 & 0.54 \\
7 & 2.25 & $1.6-2.9$ & - & - & - & - & - & - \\
\hline
\end{tabular}

show the strength of the relationship - nearly all the data points in each size range fall within the $95 \%$ confidence limits. For particles around $0.5 \mu \mathrm{m}$ radius (Fig. 5e) a correlation coefficient of $r^{2}=0.81$ was found for a $\log$-linear relationship. All other size ranges have correlation coefficients greater than 0.62 . The log-linear relationship between the particle fluxes and wind speed has the form

$$
\log (d F / d r)=a U_{10}+b
$$

where $d F / d r$ is the flux for each particle size bin, $U_{10}$ is the mean horizontal wind speed at $10 \mathrm{~m}$, and $a$ and $b$ are variables related to the particle size. Table 1 shows the values for $a$ and $b$ for each size range.

Sea spray fluxes are also often parameterized in terms of friction velocity, $u_{*}$ instead of $U_{10}$. An advantage of using $u_{*}$ is that in principle it takes account of some of the other factors that may affect the flux, such as thermal stability and wave state (Geever et al., 2005). Relationships between the fluxes for various particle sizes and the measured friction velocity have been calculated and are also summarised in Table 1 .

4.3 Comparison with sea spray source functions in the literature

The scope of this paper is to show that using the CLASP instrument along with a sonic anemometer, the net fluxes of sea spray particles can be measured across a number of wellresolved size bins. There is the potential to calculate a sea spray source function with this method but due to the limited amount of data collected during the WASFAB campaign this is not possible here. A strict comparison of the net fluxes measured during WASFAB with SSSFs from the literature requires that a correction for the deposition velocity of particles be applied. There is significant uncertainty in the deposition velocities proposed in the literature for the size of particles measured here, ranging from $0.02 \%$ at $10 \mathrm{~m} \mathrm{~s}^{-1}$ (Hopple et al., 2005) up to $30 \%$ (Slinn and Slinn, 2001). Given this high degree of uncertainty we have not attempted to correct for deposition here and simply present the measured net flux.
Figure 6 shows a comparison of the measured net fluxes with several SSSFs for wind speeds of $5 \mathrm{~m} \mathrm{~s}^{-1}, 10 \mathrm{~m} \mathrm{~s}^{-1}$ and $12 \mathrm{~m} \mathrm{~s}^{-1}$. All the source functions from the literature are applied for $80 \%$ relative humidity and denoted $d F / d r_{80}$, (i.e. particle radii are adjusted for to that which would be obtained under equilibrium conditions at a relative humidity of $80 \%$ ). The measured net fluxes have also been adjusted to a $80 \%$ relative humidity using Gerber's (1985) growth model.

Errors in direct covariance measurements are most likely due primarily to finite time averaging and to flow distortion effects (Frederickson et al., 1997). Two types of error analysis were conducted here. The first was to assess the systematic errors induced by the instruments using the compound error method outlined by Blanc (1986). This method works on the principle of examining the differences between the computed variables assuming no errors and the computed variables assuming both positive and negative errors in each input variable. These measurement errors are associated with problems in the physical measurement of a parameter due to factors such as sensor accuracy, calibration errors, flow distortion (Frederickson et al., 1997), humidity fluctuations (Gallagher et al., 1997), and particle losses down the inlet tube (Davis, 1968). To calculate the systematic error associated with fluxes of particles both the error in the measured vertical wind speed and the particle concentrations need to be determined.

The error in the vertical wind speed measured by the sonic anemometer, is quoted in the manual as $1.5 \%$ for wind speeds between 0 and $60 \mathrm{~m} \mathrm{~s}^{-1}$; this value has been used previously by Yelland et al. (1994). The error in the measured particle number concentrations for each channel of CLASP was calculated by comparing the CLASP spectra to that of the PCASP. The CLASP spectra were not consistently higher or lower than those from the PCASP which leads us to conclude that there is no systematic error in particle concentrations. The overall instrument errors for the calculated flux for each CLASP channel are shown in Table 2.

The second error analysis performed was the determination of the statistical errors in the average fluxes due to the variability of the individual estimates. It is to be expected 
Table 2. The Instrument and Statistical errors for each channel of the CLASP instrument as used in WASFAB 05.

\begin{tabular}{ccccc}
\hline channel & Instrument Errors & \multicolumn{3}{c}{ Statistical Errors $\%$} \\
\hline & & $5 \mathrm{~ms}^{-1}$ & $10 \mathrm{~ms}^{-1}$ & $12 \mathrm{~ms}^{-1}$ \\
1 & $\delta \mathrm{F}= \pm 0.17 \mathrm{~F}$ & $\delta \mathrm{F}= \pm 0.3 \mathrm{~F}$ & $\delta \mathrm{F}= \pm 0.26 \mathrm{~F}$ & $\delta \mathrm{F}= \pm 0.1 \mathrm{~F}$ \\
2 & $\delta \mathrm{F}= \pm 0.21 \mathrm{~F}$ & $\delta \mathrm{F}= \pm 0.36 \mathrm{~F}$ & $\delta \mathrm{F}= \pm 0.26 \mathrm{~F}$ & $\delta \mathrm{F}= \pm 0.68 \mathrm{~F}$ \\
3 & $\delta \mathrm{F}= \pm 0.03 \mathrm{~F}$ & $\delta \mathrm{F}= \pm 0.26 \mathrm{~F}$ & $\delta \mathrm{F}= \pm 0.3 \mathrm{~F}$ & $\delta \mathrm{F}= \pm 0.22 \mathrm{~F}$ \\
4 & $\delta \mathrm{F}= \pm 0.01 \mathrm{~F}$ & $\delta \mathrm{F}= \pm 0.6 \mathrm{~F}$ & $\delta \mathrm{F}= \pm 0.3 \mathrm{~F}$ & $\delta \mathrm{F}= \pm 0.11 \mathrm{~F}$ \\
5 & $\delta \mathrm{F}= \pm 0.02 \mathrm{~F}$ & $\delta \mathrm{F}= \pm 0.34 \mathrm{~F}$ & $\delta \mathrm{F}= \pm 0.09 \mathrm{~F}$ & $\delta \mathrm{F}= \pm 0.07 \mathrm{~F}$ \\
6 & $\delta \mathrm{F}= \pm 0.06 \mathrm{~F}$ & $\delta \mathrm{F}= \pm 0.6 \mathrm{~F}$ & $\delta \mathrm{F}= \pm 0.08 \mathrm{~F}$ & $\delta \mathrm{F}= \pm 0.13$ \\
\hline
\end{tabular}

that the statistical errors are larger than the systematic errors due to the inherent variability of turbulent flux estimates and the limited data set obtained. The statistical errors vary for wind speed and particle size covering a range from 2 to $68 \%$ however a typical error is around $30 \%$. The statistical errors are shown in Table 2 and indicated in Fig. 6.

The results from this work conform well to the SSSFs from the literature in both magnitude and size spectral shape, for all wind speeds, and in particular to Monahan et al. (1986). One notable discrepancy is that our results indicate an increase in the flux with reduction in size for the two smallest size bins whereas Mårtensson et al. (2003) and Clarke (2006) both show a decrease. This size range is near the limit of the CLASP capability and extension to smaller sizes is needed to properly evaluate the spectral behaviour of the fluxes of these particles.

The variations between sea spray source functions at different wind speeds in Fig. 6 are likely due to the use of different methods, with their own inherent uncertainties, and different environmental conditions other than wind speed: wave height, wave ages, coastal effects, stability of the atmosphere, etc. Recent formulations have shown that $u_{*}$ (Lafon et al., 2004) or wave height (Woolf, 2005) can provide better parameterisations for the whitecap fraction, which is often used in sea spray source function formulations (e.g. Monahan et al., 1986; Mårtensson et al., 2003).

Some of the differences may also be due to differing measurement heights and locations. Andreas (1998) applies to the flux at the surface and is based on Smith et al. (1993) which was developed from measurements at $14 \mathrm{~m}$ above the mean ocean surface on a sloping beach. It is noted that Smith et al. (1993) ruled out the possibility that these data were influenced by production in the surf zone. Andreas argues that the Smith et al. SSSF underestimates the true surface production and he suggested a correction. Similarly, Smith and Harrison's (1998) measurements, for particles sized 1 to $15 \mu \mathrm{m}$, were at a nominal height of $10 \mathrm{~m}$ above the ocean surface and it is suggested that the actual SSSF at the surface as defined by Andreas (1998) may be between 1.2 to 4 times their reported function. It is noted, however, that most authors use an "effective" source height of the order of $10 \mathrm{~m}$ above the mean sea surface. Andreas (2002) showed that for particles less than $2 \mu \mathrm{m}$ in radius and for wind speeds of up to $20 \mathrm{~m} \mathrm{~s}^{-1}$, the ratio between the flux at a measurement height of roughly $10 \mathrm{~m}$ and the flux near the ocean surface, at roughly $1 \mathrm{~m}$, is very small. Therefore, there is little need to correct our measurements - made $16.5 \mathrm{~m}$ above the surface for height. It is worth noting that an air-sea interface source function is important for full process level knowledge but, for many processes such as the flux of particles into the mixed layer, an effective source function at the top of the constant flux layer is sufficient.

\section{Conclusions}

The results from the eddy covariance flux system during WASFAB show strong positive correlation between the particle fluxes and the local windspeed from 3 to $12 \mathrm{~m} \mathrm{~s}^{-1}$ for particles up to a micron in radius. The flux results compare favourably with a number of recent sea spray source functions from the literature across a range of wind speeds from 3 to $12 \mathrm{~m} \mathrm{~s}^{-1}$. It was not, however, viable to calculate an independent sea spray source function from this limited series of observations.

One of the main limitations with all field measurements of sea spray particles from coastal sites is that the measurements are typically representative of only one location and one point in time; frequently the statistics are also poor due to the limited quantities of data obtained. This limitation applies here - the WASFAB field campaign lasted three weeks, but good conditions for sea spray flux measurements were obtained on only 3 days. Coastal measurement sites are generally less than ideal due to effects of the surf zone - an intense local source of sea spray particles due to much increased wave breaking compared with the open ocean (de Leeuw et al., 2000). The long pier at Duck, combined with onshore wind conditions, provided a site well away from the effects of tides or the surf zone. The drag coefficient measurements made by Zappa et al. (2006) give us confidence that this site is reasonably representative of the open ocean under the conditions encountered in this study. 
We have demonstrated the feasibility of making direct, size-resolved, flux measurements of sea spray aerosol via the eddy covariance technique for the first time. Work is ongoing to improve the size resolution of the instrument and to make measurements in the more challenging environment of the open ocean.

Acknowledgements. The work presented in this article is part of the $\mathrm{PhD}$ thesis work of Sarah Norris and was supported by TNO, The Netherlands, through the TNO OIO funds. The TNO participation in the WASFAB experiments and analysis was supported by the US Office of Naval Research, Award: N00014-96-1-0581. The Leeds participation in the WASFAB experiments was supported by the US Office of Naval Research, Unisource grant: N00014-03-1-0916. We would like to thank all the FRF personnel at Duck, particularly C. Miller, for their help and support during the WASFAB field campaign.

Edited by: W. E. Asher

\section{References}

Andreas, E. L.: Sea spray and the turbulent air-sea heat fluxes, J. Geophys. Res., 97(C7), 11 429-11 441, 1992.

Andreas, E. L.: A new Sea Spray Generation Function for Wind speeds up to $32 \mathrm{~m} \mathrm{~s}^{-1}$, J. Phys. Oceanogr., 28(11), 2175-2184, 1998.

Andreas, E. L.: A review of Sea Spray Generation Function for the Open Ocean, Atmosphere-Ocean Interactions, 1, 1-46, 2002.

Anguelova, M. D. and Webster, F.: Whitecap coverage from satellite measurements: A first step toward modeling the variability of oceanic whitecaps, J. Geophys. Res., 111, C03017, doi:10.1029/2005JC003158, 2006.

Blanc, T. V.: The effects of inaccuracies in weather-ship data on bulk-derived estimates of flux, stability and sea-surface roughness, J. Atmos. Ocean. Tech., 3, 12-26, 1986.

Blanchard, D. C.: The production, distribution, and bacterial enrichment of the sea-salt aerosol, in: The air-sea exchange of Gases and Particles, edited by: Liss, P. S. and Slinn, W. G. N., D. Reidel, Norwell, Mass, 407-454, 1983.

Blanchard, D. C. and Woodcock, A. H.: The production, concentration, and vertical distribution of the sea-salt aerosol, Ann. NY Acad. Sci., 338, 330-347, 1980.

Buzorius, G., Rannk, U., Makela, J. M., Vesala, T., and Kulmala, M.: Vertical aerosols particles fluxes measured by eddy covariance technique using condensation particle counter, J. Aerosol Sci., 29(1/2), 157-171, 1998.

Clarke, A. D., Owens, S. R., Zhou, J.: An ultra fine sea -salt flux from breaking waves: Implications for cloud condensation nuclei in the remote marine atmosphere, J. Geophys. Res., 111, D06202, doi:10.1029/2005JD006565, 2006.

Davis, C. N.: The entry of aerosols into sampling tubes and heads, British, J. Appl. Phys., 1(2), 921-932, 1968.

de Leeuw, G., Neele, F. P., Hill, M., Smith, M. H., and Vignati, E.: Sea spray aerosol production by waves breaking in the surf zone, J. Geophys. Res., 105(D2), 29397-29 409, 2000.

de Leeuw, G., Moerman, M., Zappa, C. J., McGillis, W. R., Norris, S. J., and Smith, M. H.: Eddy Correlation Measurements of Sea Spray Aerosol Fluxes, in: Transport at the Air Sea Interface, edited by: Garbe, C. S., Handler, R. A., and Jähne, B., SpringerVerlag Berlin, Heidelberg, 2007.

Desjardins, R. L., Macpherson, J. I., Schuepp, P. H., and Karanja, F.: An Evaluation of Aircraft Flux Measurements of $\mathrm{CO}_{2}$, Water Vapour and Sensible Heat, Bound.-Lay. Meteorol., 47, 55-69, 1989.

Fairall, C. W., Kerpert, J. D., Holland, G. J.: The effects of Sea Spray on Surface Energy Transports over the Ocean, The Global Atmosphere and Ocean System, 2, 121-142, 1994.

Fairall, C. W., Banner, M., Morison, R., and Persion, W.: Dependence of spray flux on breaking waves, Ocean Sciences Meeting of the American Geophysical Union, Honolulu, HI, OS53F-02, 2006.

Frederickson, P. A., Davidson, K. L., and Edson, J. B.: A study of Wind Stress Determination Methods from a Ship and an Offshore Tower, J. Atmos. Ocean. Tech., 14, 822-835, 1997.

Friehe, C. A., Williams, E. R., and Grossman, R. L.: An intercomparison of two aircraft gust probe systems, Symposium on Lower Tropospheric Profiling: Needs and Technologies, Boulder, Colorado, American Meteorology Society, 235-236f, 1988.

Gallagher, M. W., Beswick, K. M., Duyzer, J., Westrate, H., Choularton, T. W., and Hummelshoj, P.: Measurements of Aerosol fluxes to Speulder forest using a micrometeorological technique, Atmos. Environ., 31(3), 359-372, 1997.

Geever, M., O’Dowd, C. D., van Ekeren, S., Flanagan, R., Nilsson, E. D., de Leeuw, G., and Rannik, U.: Submicron Sea Spray Fluxes, Geophys. Res. Lett., 32, L15810, doi:10.1029/2005GL023081, 2005.

Gerber, H. E.: Relative-humidity parameterization of the navy aerosol model (NAM). Navel Research Laboratory, Washington, Report No. NRL Report 8956, 17 pp., 1985.

Haywood, J. M., Ramaswamy, V., and Soden, B. J.: Tropospheric aerosol climate forcing in clear-sky satellite observations over the oceans, Science, 238, 1299-1303, 1999.

Hoppel, W. A., Cafferey, P. F., and Frick, G. M.: Particle deposition on water: Surface sources versus upwind sources, J. Geophys Res., 110, D10206, doi:10.1029/2004JD005148, 2005.

Hill, M., Brooks, B., Norris, S. J., Smith, M. H., Brooks, I. M., de Leeuw, G., and Lingard, J.: A novel high-temporal resolution particle spectrometer, J. Atmos. Ocean. Tech., accepted, 2007.

IPCC: Climate Change 2001: The Scientific Basis, Contribution of Working Group I to the Third Assessment Report of the Intergovernmental Panel on Climate Change, edited by: Houghton, J. T., Ding, Y., Griggs, D. J., Noguer, M., van der Linden, P. J., Dai, X., Maskell, K., and Johnson, C. A., Cambridge University Press, Cambridge, United Kingdom and New York, NY, USA, 881 pp., 2001.

Kaimal, J. C. and Finnegan, J. J.: Atmospheric Boundary Layer flows: Their Structure and Measurement, Oxford University Press, 1994.

Kiene, R. P.: Sulphar in the mix, Nature, 402, 363-364, 1999.

Kristensen, L., Mann, J., Oncley, S. P., and Wyngaard, J. C.: How Close is Close Enough when Measuring Scalar Fluxes with Displaced Sensors?, J. Atmos. Ocean. Tech., 14, 814-821, 1997.

Lafon, C., Piazzola, J., Forget, P., Le Calve, O., and Despiau, S.: Analysis of the Variations of the Whitecap Fraction as Measured in a Coastal Zone, Bound.-Lay. Meteorol., 111(2), 339360, 2004.

Lewis, E. R. and Schwartz, S. E.: Sea Salt Aerosol Production - 
Mechanisms, Methods, Measurements, and Models, American Geophysical Union, 2004.

Massman, W. J. and Lee, X.: Eddy covariance flux corrections and uncertainties in long term studies of carbon and energy exchanges, Agr. Forest Meteorol., 113, 121-144, 2002.

Mårtensson, E. M., Nilsson, E. D., de Leeuw, G., Cohen, L. H., and Hansson, H. C.: Laboratory simulations and parameterization of the primary marine aerosol production, J. Geophys. Res., 108(D9), 4297, doi:10.1029/2002JD002263, 2003.

Monahan, E. C., Fairall, C. W., Davidson, K. L., and Boyle, P. J.: Observed inter-relationships amongst $10 \mathrm{~m}$-elevation winds, oceanic whitecaps, and marine aerosols, Q. J. Roy. Meteor. Soc., 109, 379-392, doi:10.1002/qj.49710946010, 1983.

Monahan, E. C.: Oceanic Whitecaps: Sea Surface Features Detectable via Satellite that are Indicators of the Magnitude of the Air-sea Gas Transfer Coefficient, Proceeding of Indian Academic Science (Earth Planet Science), 111, 315-331, 2002.

Monahan, E. C., Spiel, D. E., and Davidson, K. L.: A model of marine aerosol generation via whitecaps and wave disruption, in: Oceanic whitecaps, edited by: Monahan, E. C. and Mac Niocaill, G., D. Reidel Publishing Company, 167 pp., 1986.

Nilsson, E. D., Rannik, U., Swietlicki, E., Leck, C., Aalto, P. P., Zhou, J., and Norman, M.: Turbulent aerosol fluxes over the Arctic Ocean 2. Wind-driven sources from the sea, J. Geophys. Res., 106(D23), 32 139-32 154, 2001.

O'Dowd, C. D., Lowe, J. A., and Smith, M. H.: Coupling of sea-salt and sulphate interactions and its impact on cloud droplet concentration predictions, Geophys. Res. Lett., 26(9), 1311-1314, 1999.

O’Dowd, C. D. and de Leeuw, G.: Marine Aerosol Production: a review of the current knowledge, Phil. Trans. R. Soc. A 365, 17531774, doi:10.1098/rsta.2007.2043, 2007.

Reid, J. S., Jonsson, H. H., Smith, M. H., and Smirnov, A.: Evolution of the Vertical Profile and Flux of Large Sea-Salt Particles in a Coastal Zone, J. Geophys. Res., 106(D11), 12 039-12 053, 2001.
Schulz, M., de Leeuw, G., and Balkanski, Y.: Sea-salt aerosol source functions and emissions, in: Emissions of Atmospheric Trace Compounds, edited by: Granier, C., Artaxo, P., and Reeves, C., Kluwer, 333-359, 2004.

Seinfeld, J. H. and Pandis, S. N.: Atmospheric Chemistry and Physics, Air Pollution to Climate Change, John Wiley and Sons, Inc., 1997.

Slinn, S. A. and Slinn, W. G. N.: Modelling of Atmospheric Particulate Deposition to Natural Waters, in: Atmospheric pollutants in natural waters, edited by: Eisenriech, S. J., Arbor Science, Michigan, 23-53, 1981.

Smith, M. H. and N. M. Harrison: The Sea Spray Generation Function. J. Aerosol Sci., 29(supplement 1.), S189-S190, 1998.

Smith, M. H., Park, P. M., and Consterdine, I. E.: Marine aerosol concentrations and estimated fluxes over the sea, Q. J. Roy. Meteor. Soc., 119, 809-824, 1993.

Spiel, D. E.: On the births of film drops from bubbles bursting on seawater surfaces, J. Geophys. Res., 103(C11), 24 907-24918, 10.1029/98JC02233, 1998.

Stull, R. B.: An introduction to Boundary layer Meteorology, Kluwer Academic, San Diego, California, 1988.

Woolf, D. K.: Parameterization of gas transfer velocities and seastate-dependent wave breaking, Tellus, 57B, 87-94, 2005.

Yelland, M. J., Taylor, P. K., Consterdine, I., and Smith, M. H.: The use of Inertial Dissipation Technique for shipboard wind stress determination, J. Atmos. Ocean. Tech., 11, 1093-1108, 1994.

Zappa, C. J., Tubiana, F. A., McGillis, W. R., Bent, J., de Leeuw, G., and Moerman, M. M.: Investigating wave processes important to air-sea fluxes using infrared techniques, Ocean Sciences Meeting of the American Geophysical Union, Honolulu, HI, OS13C-03, 2006 . 